\title{
Sacanagem e indecência em D.H. Lawrence
}

\author{
Elizabeth Ramos
}

Difícil imaginar que uma coleção temática que se proponha a observar a tradução de textos literários eróticos não inclua alguma coisa de D. H. Lawrence (1885 - 1930), o autor de Lady Chatterley's Lover (1928), romance do qual nem mesmo a nova estética do pósguerra conseguiu eliminar a pecha de obscenidade. A sobriedade e a austeridade da era vitoriana, que se encerrara cronologicamente no início do século $X X$, haviam deixado marcas muito fortes, impedindo que as "transgressões", que põem por terra o mundo racional, pudessem ser consideradas objeto da "alta" literatura. Afinal, esculturas de falos como símbolo de força faziam parte, apenas, de "culturas africanas inferiores", e obras literárias que aludiam a sexo eram inseridas na categoria de pornográficas e imorais, destituídas de valor estético.

O invólucro cultural e o poder da patronagem, certamente, dificultam a distinção entre o erótico e o pornográfico, distinção essa que varia ao longo do espaço e do tempo. Tal é o caso, por exemplo, do próprio romance de Lawrence, e da famosa Bacchanalia de Peter Rubens considerada pintura obscena no século XVII e legitimada, mais tarde, como canônica, destituída do caráter de obscenidade. 


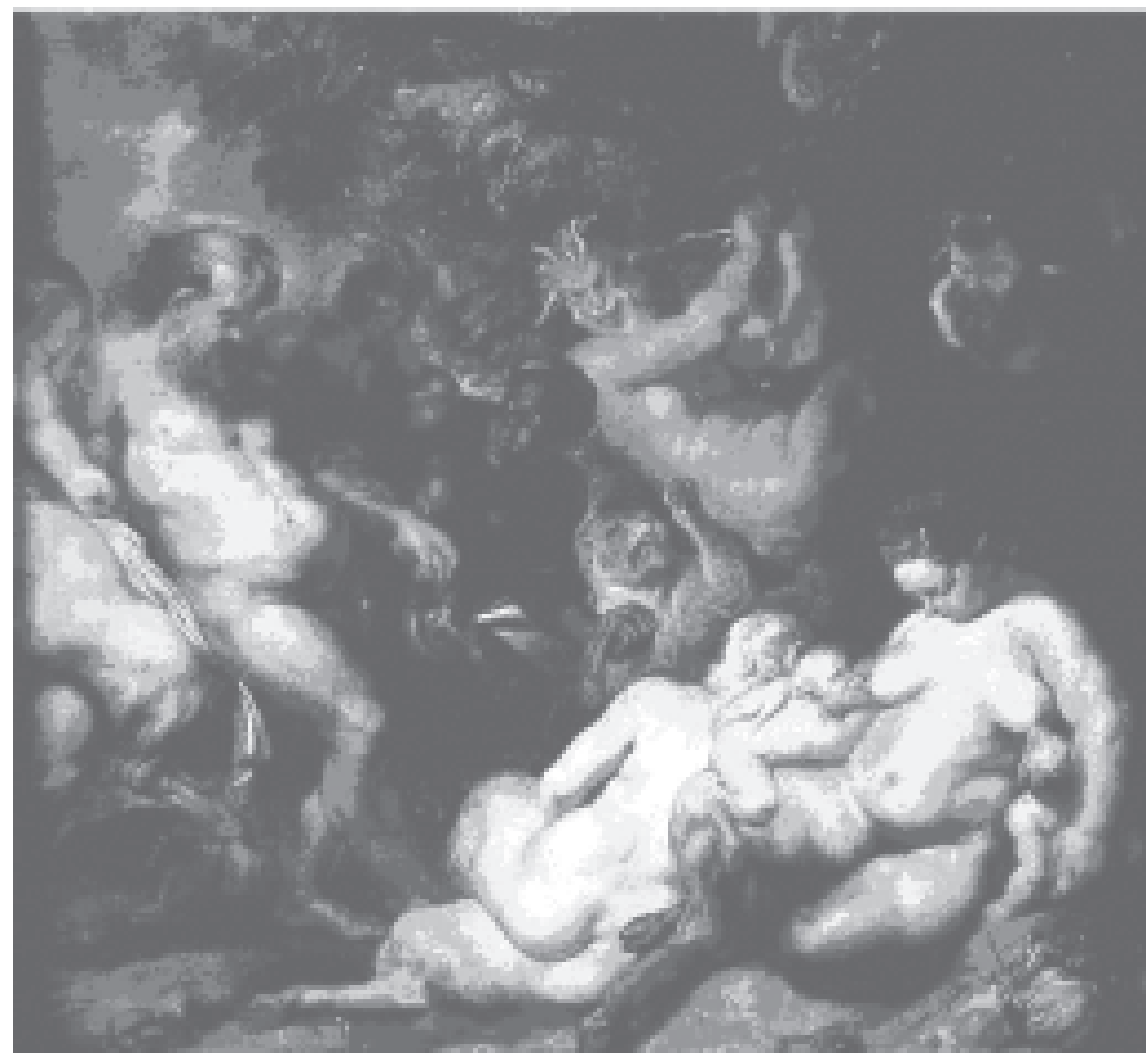

O quadro de Rubens remete o observador a algumas das reflexões suscitadas pela obra de D. H. Lawrence com relação à saúde emocional e vitalidade do sujeito, espontaneidade, sexualidade e instinto, questões suscitadas pelo pequeno poema de sua autoria "Bawdy can be sane", parte da coletânea Poesia Erótica em Tradução1, de José Paulo Paes.

O poema em inglês, que transcrevo abaixo, despertou, já em 1993, minha atenção. Na época, fiz a minha tradução, guardei-a,

PAES, José Paulo. Poesia erótica em tradução. São Paulo: Companhia das Letras, 1990, p. 144. 
cotejei-a, sem nunca a ter mostrado para o organizador da coletânea, o meu caro Zé Paulo.

\section{Bawdy can be sane}

Bawdy can be sane and wholesome, in fact a little bawdy is necessary in every life to keep it sane and wholesome.

And a little whoring can be sane and wholesome. In fact a little whoring is necessary in every life to keep it sane and wholesome.

Even sodomy can be sane and wholesome granted there is an exchange of genuine feeling.

But get any of them on the brain, and they become pernicious: bawdy on the brain becomes obscenity, vicious. Whoring on the brain becomes really syphilitic and sodomy on the brain becomes a mission, all the lot of them, vice, mission, etc., insanely unhealthy.

In the same way, chastity in its hour is sweet and wholesome. But chastity on the brain is a vice, a perversion. And rigid suppression of all bawdy, whoring or other such commerce

is a straight way to raving insanity.

The fifth generation of puritans, when it isn't obscenely is idiot. So you've got to choose. 
O poema constrói uma espécie de espelho das convicções de D. H. Lawrence, da sua relação com o sexo como equilíbrio entre mente e corpo, entre o racional e o instintivo, no sentido de conduzir à superação de insatisfações.

A tradução impõe, pois, pelo menos dois problemas derivados das polarizações: a reconstrução da leveza e do erotismo, e a contundência sutil e crescente da crítica do autor à repressão e à racionalidade da aristocracia inglesa.

Nas minhas decisões, busquei interpor esses ingredientes, colocando erotismo e contundência em caráter quase suplementar, para garantir a força da crítica. Ao assim proceder, tive a impressão de ter, algumas vezes, sacrificado a leveza, e ter dado à minha tradução a aura rústica de Oliver Mellors, o lawrenciano amante de Constance Chatterley.

\section{A sacanagem pode ser sã}

A sacanagem pode ser sã e salutar,

na verdade, uma sacanagenzinha é necessária na vida

de qualquer um

para mantê-la sã e salutar.

E uma putariazinha pode ser sã e salutar.

Na verdade, uma putariazinha é necessária na vida

de qualquer um

para mantê-la sã e salutar.

Até a sodomia pode ser sã e salutar

contanto que os sentimentos sejam genuinamente recíprocos.

Mas vá meter a razão em qualquer uma delas, e se tornam

perniciosas: 
a sacanagem racional vira obscenidade, depravação.

A putaria racional vira sifilítica

e a sodomia racional vira missão,

todas, depravação, missão, etc., insanamente doentias.

Da mesma forma, a castidade, na hora certa, é doce e salutar.

Mas a castidade racional vira depravação, perversão.

E a rígida supressão de toda sacanagem, putaria ou que tais

é o caminho mais curto para a insanidade frenética.

A quinta geração de puritanos, quando não obscenamente

é imbecil. Portanto, é só escolher.

devassa,

Ao ler a tradução de José Paulo Paes observei que, se por um lado a leveza foi preservada, por outro, o coloquialismo, como possibilidade de reconstrução da transgressão, pareceu-me perdido.

\section{A indecência pode ser saudável}

A indecência pode ser normal, saudável;

na verdade, um pouco de indecência é necessário em toda vida para a manter normal, saudável.

E um pouco de putaria pode ser normal, saudável.

Na verdade, um pouco de putaria é necessário em toda vida para a manter normal, saudável.

Mesmo a sodomia pode ser normal, saudável, desde que haja troca de sentimento verdadeiro.

Mas se alguma delas for para o cérebro, aí se torna perniciosa: a indecência no cérebro se torna obscena, viciosa, 
a putaria no cérebro se torna sifilítica

e a sodomia no cérebro se torna uma missão,

tudo, vício, missão, insanamente mórbido.

Do mesmo modo, a castidade na hora própria é normal

e bonita.

Mas a castidade no cérebro é vício, perversão.

E a rígida supressão de toda e qualquer indecência, putaria e relações assim

leva direto a furiosa insanidade.

E a quinta geração de puritanos, se não for obscenamente depravada,

é idiota. Por isso, você tem de escolher.

José Paulo Paes opta por traduzir bawdy por indecência, ao passo que minha escolha voltou-se para a linguagem 'menos polida'. Por extensão, a little bawdy e a little whoring deixaram de conter o quantitativo 'um pouco de indecência' e 'um pouco de putaria', para se tornarem diminutivos mais coloquiais em 'sacanagenzinha' e 'putariazinha'. No segundo verso, in every life passou, na minha tradução, a ser 'na vida de qualquer um', conotando a generalização, ao invés de 'em toda a vida' escolhida pelo tradutor paulista.

Minha decisão de transgredir a próclise, no terceiro verso da segunda estrofe - 'para mantê-la' - reflete o caráter de transgressão trazido por Lawrence à literatura, contrapondo-se à opção de Paes. Da mesma forma, preferi traduzir sane por 'sã', no sentido de coisa boa, e genuine feeling por 'genuinamente recíprocos' - quaisquer que sejam os sentimentos - ao invés de fazer uso de termos como 'normal' e 'verdadeiro', já que o escritor inglês contesta, no conjunto de sua obra, os conceitos de 'normalidade' e 'verdadeiro' da época. Por ter optado por traduzir sane por 'salutar', preferi manter o termo no primeiro verso da última estrofe, repetindo e enfatizando o primeiro verso do poema, em lugar de acrescentar novo adjetivo. 
Brain deixa de ser somente 'cérebro' e se torna 'razão' ou 'racional', embutindo a sobriedade vitoriana, certamente não interrompida com a morte da Rainha Vitória no início do século XX.

O prefixo de negação em unhealthy, no último verso da quarta estrofe, foi, na minha tradução, incorporado em 'doentias', diferente da opção de José Paulo Paes por 'mórbido'.

O caráter coloquial do poema é, ainda, mantido com a tradução de becomes pelo verbo 'vira', em lugar de 'se torna'.

Os dois poemas em português, com suas diferentes opções e leituras, confirmam o caráter da tradução como suplementação da obra literária, não se encerrando aqui o leque das suas ilimitadas releituras. 